\title{
Quality Development in Health Care: Participation vs. Accreditation'
}

1 Jesper Simonsen ${ }^{2}$

Professor of Participatory Design, Roskilde University, Denmark

I Morten Hertzum

Professor of Information Science, University of Copenhagen, Denmark

I John Damm Scheuer

Associate Professor, Roskilde University, Denmark

\begin{abstract}
For more than a decade, quality development in the Danish health care sector has been managed with an accreditation system known as the Danish quality model (DQM), shaping the strategy for how to align work organization with technology use. In this article, we introduce a participatory design approach, known as effects-driven information technology development (EDIT), and discuss how this approach may contribute to a new quality-assurance program for the Danish health care sector. Our purpose is to demonstrate how accreditation, which focuses on processes and standards, needs to be supplemented and balanced with participatory approaches that allow for local experimentation and implementation of high-quality outcomes. We describe accreditation and participatory design as two approaches to reconfiguring and aligning work organization and technology; further, we emphasize the differences in each approach's strategy and application.
\end{abstract}

\section{KEYWORDS}

Participatory design / work organization and technology / accreditation / Danish quality model / effects-driven IT development

\section{Introduction}

his article discusses two approaches to quality development in the Danish health care sector in relation to the introduction and use of new technologies. We compare two quality development approaches: the Danish quality model (DQM), based on accreditation, and effects-driven information technology development (EDIT), based on participatory design. We discuss how these approaches accentuate clinicians' working life, which is characterized by the constant introduction of new technologies. Accreditation is widely used within quality development in general. In the health care sector, accreditation focus on clinical processes and evidence-based standards and guidelines for these processes (WHO, 2003). Our aim is to address quality development in relation

\footnotetext{
${ }^{1}$ You can find this text and its doi at https://tidsskrift.dk/njwls/index.

${ }^{2}$ Corresponding author: Jesper Simonsen, simonsen@ruc.dk.
} 
to technology implementation and use. We argue that to support technology use in work settings, accreditation needs to be supplemented with participatory design approaches (Simonsen \& Robertson, 2013) that allow for local experimentation and implementation of high-quality outcomes.

The health care domain is complex, highly specialized, and subject to massive technology investments. These investments influence the relations between work organization and technology, which in turn transform each other (e.g., Berg et al., 2003). The introduction of new technologies is accompanied by standardization efforts to improve efficiency and quality in health care (e.g., Ellingsen et al., 2007; Klein, 2002). For example, during 2016-2017, the Capital Region and Region Zealand in Denmark have implemented the single largest information technology (IT) investment in the Danish health care sector to date (€400 million), replacing more than 30 IT systems with the Epic healthcare platform (Sundhedsplatform.dk) - an electronic health record system from the largest vendor of such systems in the US (epic.com). All departments, wards, and clinicians at all hospitals in the two regions are affected by this system, which will be used by 44,000 people in 20 hospitals. One of the goals has been to standardize the clinical guidelines by reducing 50,000 different guidelines to 5000 so that the 20 hospitals use the same clinical guidelines, embedded in the system, for workflow and decision support (Buchwaldt, 2014). The changes in the work organisation are dramatic. For the physicians, the Epic system replaces the traditional use of dictation (followed by transcription, recording, and coding by medical secretaries) with a process where the physicians themselves must write their clinical notes directly in Epic (see, e.g., Bansler et al., 2016). The physicians will also schedule all appointments and tests, a task that used to be handled by nurses and medical secretaries. New electronic health record systems such as Epic constitute a technological platform that over time will influence the work organization: The technology not only provides new means to record and access data, but it also constitutes a platform that may transform and support interdisciplinary and cross-departmental collaboration in the highly specialized areas that characterize the health care domain.

Once an IT system has been deployed, the subsequent process of making optimal use of the system is the responsibility of the quality-development organization. Quality development comprises efforts to improve the quality of processes and outcomes. In this article, we focus on the quality development associated with introducing new technologies in existing health care settings to change and improve clinical processes.

Our discussion is actualized by the fact that a new quality development program is needed for the health care sector in Denmark. Since 2005, Danish hospitals have used the process-oriented accreditation system DQM (ikas.dk; IKAS, 2013). The DQM is based on the principles of accreditation, national standards, and quality control via monitoring the primary and secondary care sectors. In 2015, the Danish Ministry of Health (Sundhedsministeriet, 2015) announced the abolition of the DQM within hospitals, a decision made in light of the criticism that clinicians spent too much time documenting care. While the alternative is yet to be developed and implemented, the Ministry of Health envisions a less bureaucratic system with fewer national goals and with a greater emphasis on outcomes. National quality goals in a new quality program should be combined with local ownership of the quality-improvement efforts. Hospitals should choose their own quality goals, have the freedom to find local methods for achieving these goals, and undertake continuous outcome-based quality improvements, including the use of real-time data (ibid).

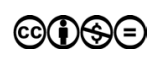


We suggest using EDIT as a local method to meet the visions of a new qualitydevelopment program. EDIT is an approach rooted in the Scandinavian tradition of participatory design (Kensing \& Greenbaum, 2013). Roskilde University and the University of Copenhagen began research on EDIT in 2004 (Hertzum \& Simonsen, 2011, 2011b). It aims to support sustained participatory design processes by focusing on the effects to be achieved by users through their adoption of a new IT system:

Simply put, the overall idea is to capture the purpose of a system in terms of effects that are both measurable and meaningful to the users, and to systematically evaluate whether these effects are attained during real use of the system. (Hertzum \& Simonsen, 2011a, p. 5)

In the following, we introduce quality development and accreditation. We describe the accreditation regime and exemplify accreditation in the Danish health care sector using the DQM's accreditation requirements for cross-departmental patient transfers. We describe the EDIT approach using an elaborated example of patient transfers focusing on the concrete effect of obtaining 'fasting periods closer to the required six hours before operation' - an effect related to tighter cross-departmental coordination mediated by new technologies. Finally, we discuss and compare the two quality development approaches: accreditation through DQM and participatory design through EDIT.

\section{Quality development and accreditation}

Quality development involves the improvement of processes and outcomes, that is, measuring where you are, and figuring out ways to make things better (also referred to as quality improvement), ensuring that processes and outcomes comply with certain guidelines, requirements and standards (also referred to as quality assurance), as well as approaches to manage the overall quality development process (also referred to as quality management). The historical roots can be traced back to Taylorism and the scientific methods of establishing and institutionalising mass production and repetitive processes and work practices entailing a focus on the production processes. The inherent logic for systematic process-focused quality development is the quality cycle consisting of the

Figure I. The four phases in the PDCA circle: (I) plan, (2) do, (3) check, and (4) act.

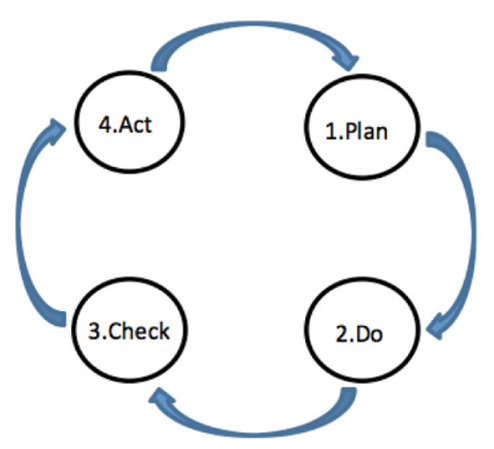


phases plan-do-check-act (PDCA), see Figure 1. The PDCA circle was originally proposed by Deming (1982), and it is now widely used in quality development in general (Sokovic et al., 2010) as well as in the health care sector (Taylor et al., 2014), where it, among others, is part of LEAN initiatives (Eriksson et al., 2016).

Standardization in the form of policies, standards, guidelines, procedures, and pathway packages is a popular quality-improvement strategy among health care leaders, and one way of promoting standardization is through accreditation (Bogh et al., 2016). Accreditation means, according to Merriam-Webster (merriam-webster.com), 'to give official authorization to or approval of', 'to provide with credentials', 'to recognize or vouch for as conforming to a standard'. Accreditation refers to a method of quality development where an organization's compliance with quality standards is evaluated through external audits (Mainz et al., 2011).

Accreditation was in 2005 established as the national approach to quality development in the Danish health care sector using a quality model (DQM) - following the PDCA circle illustrated in Figure 1 - institutionally maintained by the Danish Institute for Quality and Accreditation in Healthcare (IKAS, 2013). The aim of the DQM is to improve the quality of clinical pathways, to make the quality of the health care sector visible and transparent, and to improve clinical, organizational, and patient-perceived quality. An additional aim is to foster learning and quality development in the health care sector through the continuous evaluation of hospitals and other health care organizations.

The DQM covers multiple areas of the Danish health care sector, including hospitals, general practice, dentists, and pharmacies. The accreditation standards for hospitals are comprehensive and divided into organizational standards, general standards related to clinical pathways, and standards related to patient diagnoses. The standards are related to the phases of the PDCA circle (see Figure 1), with one indicator for each phase. The 'plan' indicator checks whether the hospital has a document that describes how the quality goal of the given accreditation standard is to be obtained. The 'do' indicator checks whether the hospital has implemented the standard. The 'check' indicator examines whether the hospital monitors the quality of the hospital's structures, processes, and delivered services. Finally, the 'act' indicator checks whether the hospital evaluates the results from the monitoring and has prioritized and taken action in cases where quality problems have been identified.

For example, the standard for 'information in relation to the transfer of patients between departments and hospitals' is described as follows: 'When a patient is transferred to another department at the same or a different hospital, relevant and sufficient information is passed on' (IKAS, 2013, p. 162). The standard explains that all hospitals should, as a minimum, have a guideline describing the kinds of information that should be passed on. This guideline should, as a minimum, provide an overview of the information to be documented and passed on when patients are being transferred. The standard explains that all departments involved in the treatment of patients must use it. As prescribed, four indicators relate to the standard. The 'plan' indicator explains what the auditor should check for: 'There exists a guideline for transfers between departments and hospitals' (ibid, p. 162). The 'do' indicator points out that what the auditor should look for is 'when patients are transferred, relevant information is passed on in accordance with the hospital's guideline' (ibid, p. 162). The 'check' indicator is formulated as 'the hospital has goals for the quality of information passed on when patients are transferred between departments and hospitals, and whether goals met are evaluated at least twice during a

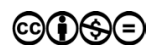


three-year period, using quantitative or qualitative methods or a combination of these' (ibid, p. 162). Finally, the 'act' indicator states that the auditor should determine whether 'the hospital has taken steps to improve the quality of the information passed on' in case the guideline is not followed or the stated goals are not met (ibid, pp. 162-163).

According to WHO, '[a]ccreditation is the most commonly used external mechanism for standards-based quality improvement in health care' (WHO, 2003, p. 103), and a core element is the PDCA circle (WHO, 2006). Accreditation is supported by international organizations such as the International Organization for Standardization (iso.org), the International Accreditation Forum (iaf.nu), the European Co-operation for Accreditation (european-accreditation.org), and Quality assurance in healthcare (ISQua. org). ISQua is dedicated to the health care sector, has 70 member countries (Greenfield \& Braithwaite, 2008), including Denmark. While accreditation has been the national strategy for quality development in Denmark, this is not the case in the other Nordic countries and the main experience of accreditation in the Nordic countries is from Denmark (Engel \& Andersen, 2017). A few Nordic hospitals have adopted accreditation from the Danish DQM model, including hospitals on the Faroe Islands (IKAS, 2014) and in Norway (IKAS, 2015), but this has not yet been reported on in the scientific literature. A few publications report from accreditation used in local Nordic settings, including in the Swedish primary care, introduced in 2009 (Norén \& Ranerup, 2015) and the Norwegian occupational health care, where accreditation was implemented in 2010 (Lie \& Bjørnstad, 2015). Accreditation has been a crucial instrument to promote competition among Swedish primary care centres (Norén \& Ranerup, 2015). Care centres need to comply with a set of minimum accreditation standards decided by the regional politicians. This has driven care centre managers to focus on their scores on the accreditation quality indicators and the resulting rankings as these evaluations are public and used by citizens in choosing a care centre and by the media to rank the centres. Lie and Bjørnstad's (2015) survey of 228 accredited Norwegian occupational health services concludes that the accreditation system was accepted and improved their services. The results show that $42 \%$ had made adjustments to achieve accreditation. Fifty-one percent were satisfied with the accreditation process, while $19 \%$ were dissatisfied.

An international literature review (Greenfield \& Braithwaite, 2008) reveals that accreditation also is viewed as bureaucratic and time-consuming and that findings are inconsistent regarding the clinicians' attitudes to - and the organizational impact of accreditation. Research on the Danish accreditation experience show that the introduction of the accreditation system has led to improved patient care (Bogh et al., 2016) and that high compliance with accreditation standards is associated with a higher level of evidence-based hospital care (Falstie-Jensen et al., 2017). The reason why accreditation has been partially discontinued in 2015 is, according to Engel and Andersen (2017), that the accreditation program over time has led to overimplementation and bureaucracy. Especially physicians have become very critical and $63 \%$ mainly associate accreditation with 'control/monitoring', and only 33\% with 'quality improvement' (4\% answered that 'they don't know'). Ehlers et al. (2017) explain the negative attitude toward accreditation as:

While standardization of procedures is indeed an important component of accreditation, standardization and in particular management by monitoring compliance of actual processes with specifications was taken too far, leading to a 'control and checklist culture'. 
Part of the reason may have been that hospital managers tried to safeguard themselves against criticism, and assure a positive external evaluation. Clinical departments seemed insufficiently involved in defining the application of the standards, or interpreting them in a clinically meaningful manner. (Ehlers et al., 2017, p. 5)

This explanation is complemented by a recent publication from ISQua where it is noted that:

Organizations must 'own' the standards as well as the improvement process and not wait for an external body to come and evaluate them every few years. This is not about doing something 'for accreditation', it is about doing something to improve quality of care and patient safety. The imperative is to move away from the traditional view-one of viewing accreditation as an 'event' or 'project'. (Nicklin et al., 2017, p. 311)

\section{EDIT: A participatory design approach to quality development}

Participatory design is a research field that focuses on how 'users' (employees, citizens, clinicians, patients, etc.) actively may participate in the design, implementation, and use of IT, which increasingly influences and changes our society. Participatory design has roots in Scandinavian sociotechnical movements (Bjerknes et al., 1987; Greenbaum \& Kyng, 1991). Participatory design shares interests with Nordic working life research, especially regarding workplace democracy, representation of interests, and focus on learning (Hvid et al., 2011) and user, or employee-driven approaches to innovation (Ramstad, 2015; Wihlman et al., 2014). Participation is traditionally connected to equal power relations, democracy, work-life quality, and mutual learning techniques (Kensing \& Greenbaum, 2013). Participatory design has political, emancipatory and pragmatic motivations, and rationales by emphasizing a principle of active participation in having a direct impact on the design process (Bannon \& Ehn, 2013). The political and emancipatory perspectives on the user-participant's democratic right to influence one's own living and working conditions (Ehn, 1988) are often operationalized into pragmatic and practical issues centered on user participation in decision-making activities that influence the process of design as well as the guiding visions and resulting outcomes (Bratteteig \& Wagner, 2016; Bødker et al., 2004).

EDIT is a sociotechnical instrument for managing IT projects (Hertzum \& Simonsen, 2011a), rooted in the participatory design tradition, and, as much of the Nordic working life research, through a series of action research projects (Peter Hasle, 2013). In Scandinavia, sociotechnical approaches to IT development builds on Nygaard's (1979; 1996) seminal research to ensure employee influence on IT projects through trade union participation in the projects. The basic premise of these approaches is that the introduction of new IT systems in the workplace is inextricably intertwined with changes in the work conditions and ways of working. While the early research construed the relation between employees and management from a conflict perspective (e.g., Bjerkness et al., 1987), later research has emphasized the mutual benefits of employee participation on working-life quality and system quality (e.g., Bødker et al., 2004). EDIT has been developed in collaboration with the Danish health care regions over the last decade (Hertzum 
\& Simonsen, 2011b). EDIT was initiated as an approach to the development and implementation of health care IT systems with a focus on the effects that using these systems should have (Simonsen \& Hertzum, 2008; 2016). EDIT has been developed to form an alternative strategy to quality development supporting local participatory attempts to quality improvement in sociotechnical environments: EDIT emphasizes a sustained participatory design approach to the everyday use of IT, including changes to the work organisation as well as reconfigurations of the systems, that is, a general quality development approach focusing on improving work organization and technology (Simonsen $\&$ Hertzum, 2012).

In short, EDIT concerns the specification of desired effects by local clinicians and their management in relation to using available technologies; the realization of these effects through local experimentation and intervention; and the formative evaluation and assessment of whether the effects are achieved. This overall process is outlined in Figure 2.

Figure 2. Overall process of EDIT: A participatory design approach to quality development (Hertzum \& Simonsen, 201 la, p. 6).

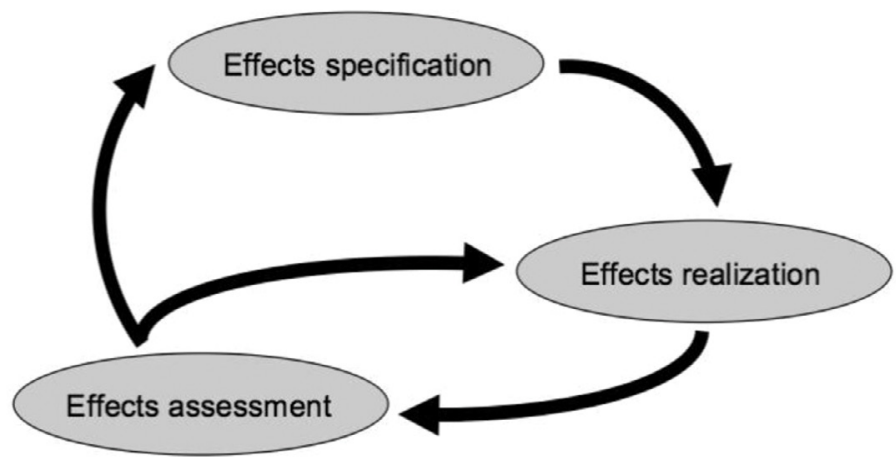

During effects specification, the users (and their managers) specify and prioritize the effects that they would like to obtain by using a specific IT system. These effects may be specified through workshops, and a desired effect may comprise a description of the effect, how the effect can be measured, the current status for obtaining the effect, a plan for the intervention needed to obtain the effect, who is responsible for the intervention, any known barriers and challenges for obtaining the effect, a list of stakeholders, etc. (Simonsen et al., 2011).

Effects are realized through interventions where work processes and organization are changed and technology support is provided. The process of realizing effects might comprise new or reconfigured cooperative procedures, new or reconfigured technologies, and communicating and implementing new practices for using the technologies.

Finally, and importantly, the effects are assessed periodically or, if possible, continuously on the basis of real-world data (Brandrup et al., 2017). Continuous assessment may be possible if information about whether the effect is obtained can be extracted 
automatically from the system and visualized in a manner that shows the evolving effectachievement status. Alternatively, effects data might be collected through the use of addon applications dedicated to data capture and visualization (ibid).

EDIT comprises an overall management instrument targeting specific and concrete results through an ongoing iterative process of interventions, including changes to the work organization and the systems in use. It also supports a participatory design process by involving users in all three key activities shown in Figure 2. Although the effect (the target and outcome) is clearly identified, the way to obtain the effect (the process) is worked out by iteratively experimenting with different interventions, as indicated by the arrows in Figure 2.

Along with the iterative process, EDIT provides a means-end hierarchy to align effects to overall goals (see Table 1). The means-end hierarchy originates from cognitive systems engineering (Rasmussen et al., 1994) and has been adapted to the strategic alignment analysis in participatory design projects (Bødker et al., 2004). By relating the specified effects to the hierarchy, it becomes visible how they (as means to an end) align and comply with national and regional goals. The example effect of shorter fasting periods (i.e., fasting periods that begin little more than the required 6 hours before operation) in Table 1 can be read from top to bottom, keeping in mind that Denmark (i.e., the national and regional political level) subscribes to Michael Porter's overarching health care sector strategy, known as value-based health care delivery (Porter, 2008). By pursuing this effect, a regional hospital improves the patients' experience of mandatory fasting and reduces postoperation complications. Three clinical processes that are well known to clinicians are involved: pre-medication, preoperation care, and the operation process. The clinical work processes that are critical to obtaining the effect are the decision process of prioritizing patients for operation and the ongoing planning and coordination of fasting times for each individual patient according to her operation plan. Finally, the technology that supports the cross-departmental overview of patients and

Table I EDIT's means-end hierarchy with the example effect of achieving shorter fasting periods

\begin{tabular}{ll}
\hline Means-end hierarchy & Relating shorter fasting periods to national goals \\
\hline $\begin{array}{l}\text { National level } \\
\text { (environment: political demands, national }\end{array}$ & $\begin{array}{l}\text { Value-based healthcare delivery } \\
\text { goals, standard guidelines, etc.) }\end{array}$ \\
Regional/hospital level & - Patient experienced value (less hunger and thirst) \\
(strategy: relation/response to & - Fewer postoperation complications \\
environment) & - Shorter recovery period \\
Clinical process & - Pre-medication process \\
(recurrent, familiar input-output & - Preoperation care \\
relationships) & - Operation \\
Clinical activity & - Prioritizing patients for operation \\
(work process: critical with regard to & - Planning and coordinating fasting time according to \\
technology support) & operation plan \\
Technology & Cross-departmental overview of patients' schedule for \\
(IT platform needed to support clinical & operation and their respective fasting times \\
activity) &
\end{tabular}


their fasting times is indicated (bottom of Table 1) as the technological means to achieve the effect and meet the national goal set for the hospital.

The means-end hierarchy documents the argument chain of local quality development initiatives' relation to national/regional goals. The national and regional levels reflect relatively stable goals, while the levels of clinical processes, activities, and technology outline the application area for the experimental and iterative EDIT process (Figure 2).

\section{Example: EDIT at a hospital}

EDIT was used at Nykøbing Falster Hospital in Denmark in 2014-2015 to optimize patient transfers between departments (please note that the accreditation example given in the section above describes the equivalent DQM standard for patient transfers (IKAS, 2013, p. 162)). This project involved researchers (including authors of this article) in collaboration with clinicians from the hospital. Nykøbing Falster Hospital had recently deployed electronic whiteboards in all its departments to facilitate the clinicians in maintaining an overview of the patients currently in their department. The whiteboards might be viewed as a simple example of the large-scale infrastructures that seek to enable new forms of interdisciplinary and cross-departmental collaboration, such as the Epic health care platform.

The whiteboard is highly configurable and can display information targeted to the needs of individual departments, including patient location (room), triage level, diagnosis, responsible physician/nurse, status of the clinical care plan, and blood test results (Rasmussen et al., 2010). In addition to supporting internal departmental communication and coordination, the whiteboard may support communication and coordination among departments. One of the overall aims of deploying the whiteboards throughout the hospital was to support patient transfers between departments. The project was initiated in the autumn of 2014 by involving departments requiring the tightest coordination regarding patient transfers: the department performing the surgeries and the departments with patients admitted for parenchymal and orthopedic surgical treatment.

In the autumn of 2014, the researchers held a series of workshops with physicians, nurses, and secretaries to specify the effects they would like to pursue - their 'wished-for effects'. Both managing and ordinary clinicians participated in the workshops. Effects were specified through initial brainstorming, followed by discussion, gradual refinement, and prioritization. During the workshops, the clinicians identified, discussed, and specified nine effects, one of which was 'fasting periods closer to the required six hours before operation'. Patients must fast (abstain from food) for at least 6 hours before they undergo anesthesia; however, most patients fast considerably longer than 6 hours because of complexities in operation planning, including the postponement and cancellation of planned surgeries due to the arrival of more severe acute cases. Shorter fasting periods is an important effect for several reasons:

- It is a concrete, well known, and common problem that is generally acknowledged among clinicians and directly related to the quality of patient treatment (i.e., the national and regional/hospital levels in Table 1).

- The physicians know that long fasting periods are a threat to patients' health and recovery. 
- The nurses experience, almost on a daily basis, patients who are frustrated because they have been fasting for 10,12, or 15 hours and still do not know when they will undergo surgery.

- Optimizing the fasting period involves coordination related to the transfer of patients to the operating department, thereby providing a good match with the project's overall aim of utilizing the whiteboards to optimize patient transfers.

The way to realize this effect, however, is complex and requires changing the procedures and practices for negotiating, coordinating, and communicating operating schedules, planning, and patient transfers. Throughout 2015 , the researchers met with a core group of three clinicians every second week to plan and follow-up on the realization of the effect and to prepare for assessing it. The core group of three clinicians was established to (1) analyze the involved departments' procedures and practices, (2) suggest interdepartmental models of cooperation, (3) initiate new cooperative procedures and terminology, (4) reconfigure the whiteboards to support the realization of the effect, (5) communicate new ways of using the whiteboards, and (6) monitor, evaluate, and follow-up on changes, interventions, and the need for further initiatives. During 2015, the group completed two iterations of steps 1-6.

The effects assessment was conducted both continuously and periodically. The whiteboards were reconfigured to display when a patient began fasting and how many hours and minutes that had elapsed since the start of the fast. This way, the clinicians had continuous access to the fasting status of each patient scheduled for surgery and could take this information into account when planning the patient's trajectory. Periodically, the recorded start and end of the fast can be used as input for reports showing fasting period statistics for different groups of patients, including the average length of fasting for the patients last week, for parenchymal or orthopaedic surgeries, for acute or planned surgeries, etc.

The effects assessment resulted in insights into the work organization, collaboration, and status of patient fasting times. Three interventions were suggested to improve the fasting times: (1) interdisciplinary team meetings at the whiteboards where the operation coordinator (a nurse) meet with the surgeons in charge of parenchymal and orthopedic operations and the physician managing anesthesiology to collaboratively walk through the patients and prioritize the operations; (2) a reorganization of the planning of elective patients for pre-planned operations; and (3) a change in the way patients are informed prior to planned operations.

\section{Discussion}

DQM and EDIT represent two different quality development approaches to work organization and technology. DQM aims at quality assurance through accreditation based on documented process standards, while EDIT uses a participatory approach to obtain the desired effects through the technology-supported improvement of clinical work. In the following, we compare DQM and EDIT with respect to their strategy, application, challenges, and potential meeting points, as summarized in Table 2. DQM and EDIT differ in multiple important respects and, consequently, one cannot replace the other. Rather, the aim of the comparison is to clarify how they differ and where they may complement each other.

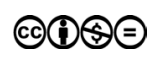


Table 2 A comparison of DQM and EDIT

\begin{tabular}{|c|c|c|}
\hline Characteristic & DQM & EDIT \\
\hline Aim and concern & $\begin{array}{l}\text { National quality goals achieved } \\
\text { through evidence-based or 'best } \\
\text { practice' process standardization }\end{array}$ & $\begin{array}{l}\text { Local quality goals achieved through } \\
\text { realizing effects aligned with national } \\
\text { quality goals (see Table I) }\end{array}$ \\
\hline Strategy & $\begin{array}{l}\text { - Behavior control } \\
\text { - Standardization of processes by } \\
\text { indicators of the PDCA phases } \\
\text { (see Figure I) } \\
\text { - Documenting and complying with } \\
\text { standard procedures } \\
\text { - Top-down control approach by } \\
\text { external auditors }\end{array}$ & $\begin{array}{l}\text { - Outcome control } \\
\text { - Standardization of output by speci- } \\
\text { fying, realizing, and assessing effects } \\
\text { (see Figure 2) } \\
\text { - Local experimentation to realise } \\
\text { effects } \\
\text { - Bottom-up participatory learning } \\
\text { approach by local clinicians }\end{array}$ \\
\hline \multicolumn{3}{|l|}{ Application (Weick, 2000) } \\
\hline - Gets people to act & $\begin{array}{l}\text { By directing attention toward docu- } \\
\text { menting and learning the accredita- } \\
\text { tion standards and by auditor visits } \\
\text { every third year }\end{array}$ & $\begin{array}{l}\text { Through involving people in specify- } \\
\text { ing and prioritizing measurable, } \\
\text { wished-for effects on an on-going } \\
\text { basis }\end{array}$ \\
\hline - Gives people a direction & $\begin{array}{l}\text { People should learn and comply with } \\
\text { the standards. }\end{array}$ & $\begin{array}{l}\text { People should systematically pursue } \\
\text { the wished-for effects. }\end{array}$ \\
\hline $\begin{array}{l}\text { - Supplies legitimate } \\
\text { explanations }\end{array}$ & $\begin{array}{l}\text { Legitimate explanations from the } \\
\text { 'outside'; approval/accreditation to } \\
\text { enable actions to become routine }\end{array}$ & $\begin{array}{l}\text { Effects specified from the 'inside' form } \\
\text { legitimate explanations that have the } \\
\text { potential to become routine. }\end{array}$ \\
\hline Skill acquisition & $\begin{array}{l}\text { Novices, advanced beginners, and } \\
\text { competent clinicians }\end{array}$ & $\begin{array}{l}\text { Novices, advanced beginners, } \\
\text { competent, proficient and expert } \\
\text { clinicians }\end{array}$ \\
\hline Challenges & $\begin{array}{l}\text { - To implement general standards } \\
\text { in specific and concrete work } \\
\text { contexts } \\
\text { - Lack of motivation and engage- } \\
\text { ment from local clinicians }\end{array}$ & $\begin{array}{l}\text { - To generalize and disseminate local } \\
\text { processes that succeed in obtaining } \\
\text { wished-for effects } \\
\text { - Lack of top management attention } \\
\text { and resource allocation }\end{array}$ \\
\hline Meeting point & $\begin{array}{l}\text { Global aims, goals, and standard } \\
\text { clinical guidelines that need to be } \\
\text { obtained/implemented locally }\end{array}$ & $\begin{array}{l}\text { Local experimentation to obtain } \\
\text { effects as an implementation strategy } \\
\text { to align global aims, goals, and stan- } \\
\text { dard clinical guidelines }\end{array}$ \\
\hline
\end{tabular}

\section{Strategy}

DQM focuses on ensuring that processes and clinical standards are present and that the clinicians comply with them. DQM builds on the PDCA circle (see Figure 1) assuming that if process standards are documented, and compliance with the standards is assessed, then the quality of the hospital's services and outcomes, including patient treatment and patient safety, will improve.

In EDIT, the connection between results and processes is the reverse. EDIT assumes that the local processes that cause certain effects are complex and must be 'discovered' 
during an iterative participatory design process. Some standards and processes performed in certain ways may yield the wished-for effects, while others may not. The needed interventions and the specific relationship between local processes, standard guidelines, and wished-for effects are open and empirical questions.

Organizational management theory distinguishes between behavior control and outcome control (Eisenhardt, 1985), which correspond to two different coordinating mechanisms: the standardization of work processes and the standardization of outputs (Mintzberg, 1980). Behavior control is an effective management strategy if the work in the organization can be planned and 'programmed' in detail so that behaviors (processes) can be explicitly defined and readily measured (Eisenhardt, 1985, pp. 135f). This corresponds to Mintzberg's (1980) standardization of work processes: 'Work is coordinated by the imposition ... of standards to guide the doing of the work itself - work orders, rules and regulations, etc'. (p. 324). If the organization's tasks are more situated, characterized by exceptions and the need for ongoing adjustments, then behavior and process strategies are less effective. More general process standards might be applied, but their practical and local implementation will depend on the context and situation. In contrast, outcome control is an appropriate management strategy if the goals or outcomes of the organisation's work can be clearly stated and measured (Eisenhardt, 1985, pp. 136ff). This corresponds to Mintzberg's (1980) standardization of outputs: 'The work is coordinated by the imposition ... of standard performance measures or specifications concerning the outputs of the work' (p. 324).

DQM and its standards focus on ensuring that certain processes are present and take place in certain ways. That is, DQM relies on behavior control (Eisenhardt, 1985) and on the standardization of work processes (Mintzberg, 1980). In EDIT, the relation between results and processes is the reverse - that is, a strategy of outcome control (Eisenhardt, 1985) and the standardization of outputs (Mintzberg, 1980). According to Mintzberg (ibid), the organizational form of hospitals is the professional bureaucracy, with highly specialized clinicians who have considerable autonomy in their work. Hospitals, like for instance universities, rely on a coordination mechanism that consists of the standardization of skills. Through its focus on external control and the standardization of processes, DQM pushes the hospitals toward the organizational form of the machine bureaucracy. In contrast, EDIT, relying on the standardization of outputs, pushes the hospitals toward the divisionalized form, with specified interfaces between divisions each of which might remain a professional bureaucracy.

\section{Application}

According to the organizational psychologist Karl E. Weick (2000), any quality improvement framework will improve performance if the framework accomplishes three things (p. 163):

1. 'Gets people to act'. That is, the framework engages and motivates people to participate in actions that aim at improving the quality of their work and work context.

2. 'Gives people a direction (through values or whatever)'. That is, the framework provides people with some kind of map, course, and objective to help them orient toward the quality goal they would like to achieve. 
3. 'Supplies legitimate explanations that are energizing and enable actions to be repeated and over time become "routine"'. Such explanations motivate, support, and justify that new ways of working are gradually incorporated in routines and, eventually, implemented as standard procedures and guidelines.

In DQM, people document and learn the accreditation standards so that the hospital will be accredited when the auditors visit every third year. Failure to pass the accreditation audit has serious consequences: Critical remarks from the auditors must be followed up on before the accreditation is passed, and failure to pass the accreditation might, as an extreme consequence, lead to closing hospital departments. Hospitals' executive boards are responsible for the accreditation, and the actions needed to prepare and pass the accreditation are given top priority. During the auditor visit, most clinicians on call experience an atmosphere similar to that of an examination. The actions clinicians are impelled to take have to do with knowing, learning, performing, and complying with the accreditation standards. The standards are documented and approved as part of the accreditation. For example, one approved clinical standard for hand hygiene is a 28-page document describing when, how, and why to maintain high-quality hand hygiene to prevent infections at hospitals (Clearinghouse, 2009). Legitimate explanations in the DQM are given as part of the standard documentation and comprise clinical arguments and accreditation demands. For the hand hygiene standard, the description of the problems that the guideline aims to prevent references 68 scientific articles with supporting evidence (ibid). Along with this explanation from the 'outside', explanations are driven by the need for regular reaccreditation.

EDIT prompts people to act through involving them in improving their own work situation. The participatory approach involves them in analyzing their own work situation by identifying, prioritizing, and specifying effects they would like to realize to improve the situation. The participants identify measurable wished-for effects, which make sense to those involved and provide a shared sense of direction. There is also a good chance that the actions to realize an effect make sense to those involved because the actions are the result of a collective process of analyzing and deciding on the interventions they believe are required. The interventions are empirically tested through iterative experiments and measurements. The clinicians' reasons for prioritizing the effect of shorter fasting periods provide legitimate explanations from the 'inside' and foster ownership of the direction (the specified effect) as well as the routinization (the realization of the effect). Routines that result in wished-for effects might be documented as standard guidelines.

\section{Skill acquisition}

With its focus on process standardization, DQM leads to the formulation and introduction of procedures for clinicians to follow. The rationale for these procedures includes the dissemination of 'best practices', the prevention of errors by consistently following the procedures, and the management of turnover by having explicit procedures that are similar across hospitals. Benner (1982) emphasizes that the standardization and routinization of procedures reflects and reinforces competent performance, which in her model is the third of five levels of performance. 
Due to their lack of experience, 'novices' (level 1) cannot use discretionary judgment, and they therefore need procedures that can guide their actions without presupposing past experience with similar situations. Novices are severely restricted in their performance because they can merely apply procedures in a context-free manner rather than in response to the demands of the concrete situation. While 'advanced beginners' (level 2) have begun to perceive patterns in their clinical practice, they cannot yet sort out what is most important in a situation. Like the novice, the advanced beginner needs guidance from procedures and supervision by more experienced colleagues. 'Competent clinicians' (level 3) respond to situations and manage the contingencies of these situations by conscious, deliberate planning. Their approach is analytic and characterized by the identification of clinical goals, the formulation of plans to achieve the goals, and the organized execution of the plans. The norms inherent in the DQM and the on-thejob training arising from it are well aligned with competent performance and facilitate novices and advanced beginners in advancing to the level of competent performance.

Advancing beyond the level of competent performance appears to be outside the scope of DQM, which may even stand in the way of proficient and expert performance, or, as other studies of standardisation efforts in the health care domain have shown, making highly skilled work invisible (Kamp \& Dybbroe, 2016). The 'proficient clinician' (level 4) no longer performs by consciously formulating and executing plans; rather, the proficient clinician will be immersed in her activities and experience them from a perspective shaped by past events. This perspective makes certain features of the current situation stand out as salient while others recede into the background. Dreyfus and Dreyfus (1986, p. 28) explain that 'no detached choice or deliberation occurs. It just happens, apparently because the proficient performer has experienced similar situations in the past and memories of them trigger plans similar to those that worked in the past and anticipations of events similar to those that occurred'. While the proficient clinician resorts to analytic thought to verify or explain her activities, the 'expert' (level 5) relies fully on her intuitive grasp of the situation and will, if prompted for an explanation, typically say something like 'because it felt right' (Benner, 1982, p. 405). That is, she will be disinclined to analytic deliberation, except when experiencing situations that are novel. Providing proficient and expert clinicians with rules and procedures to follow leaves them somewhat frustrated. For example, a group of nurses felt that the standard procedure for patient triage did not respect their professionalism because it sidestepped their experience and clinical gaze (Ernst, 2016). In such situations, proficient and expert clinicians will often give examples of situations in which the rules and procedures are clearly invalid (Benner, 1982).

In contrast to the DQM, EDIT focuses on the ends (i.e., effects), for which work processes are the means. This focus accommodates variety in the clinicians' work processes, for example, those that are dependent on differences in skill level. Specifically, the achievement of ambitious effects may require means other than standard procedures if the proficient and expert clinicians are to perform their best.

\section{Challenges}

While the openness to and experimentation with processes to obtain effects may support proficient and expert clinicians in their working styles, this approach also entails a challenge: How can successful local experiences feed into an overall quality-assurance 
program, inspire other clinicians to follow the example and be distributed throughout the organization? After the wished-for effects have been successfully achieved locally at a hospital or a ward, EDIT offers no specific support for disseminating these effects (and the processes and interventions that led to them) to other wards or hospitals. The knowledge transfer in this case will rely on establishing and maintaining forums to share experiences, supplemented with documentation of the processes, and interventions that locally have been the means to achieve the effects. The latter resembles generalizing these processes into standard clinical guidelines described at a level of abstraction that meets the needs of clinicians at different skill levels.

This challenge is somehow reversed with regard to DQM. Here, the starting point is the dissemination of 'best practices' by documenting generic processes as standard clinical guidelines to be followed. The challenge for DQM is to implement general process standards in local work contexts characterized by highly skilled work, constant exceptions, and continual assessment and decision making. In addition, accreditation through DQM involves a mandatory, top-down control approach by external auditors to enforce the implementation; this approach has been met with a lack of motivation and engagement from local clinicians. EDIT might address this disapproval. However, as a local, bottom-up participatory approach, it must be expected to face challenges concerning resource allocation and lack of top management attention - unless EDIT gains national or regional recognition.

\section{Meeting point}

The challenges that DQM and EDIT face, respectively, also indicate a potential meeting point for these quite different approaches to quality development. A need for a process-oriented quality program like DQM remains, even though formally DQM has been abolished for Danish hospitals (the secondary health care sector). National political decisions result in new aims and goals, such as the Danish cancer pathway program (Ingeman et al., 2015). Initiated by parliament, it offers all patients a national standard program within guaranteed deadlines. Such programs form a mandatory overall clinical guideline that needs to be implemented locally throughout the healthcare sector. New research regularly documents that specific clinical outcomes can be obtained, provided that certain guidelines are implemented. Sometimes, evidence-based guidelines also include detailed procedures, like those related to hand hygiene (e.g., how to use a paper towel) (Clearinghouse, 2009, p. 9). Implementing evidence-based guidelines that include such detailed work procedures is not an appropriate application domain for EDIT. Rather, EDIT addresses overall (i.e., national or regional) goals or mandatory high-level clinical guidelines that need to be realized locally. In the example with the effect of obtaining a shorter fasting period, a prime motivation for the clinicians was their knowledge of the research evidence pointing to clinical complications of long fasting periods. Local experimentation to obtain effects may help address the implementation challenges experienced with DQM, as a way to combine standardization with self-management principles (Oudhuis \& Tengblad, 2013). For example, the participatory approach driven by local clinicians aims to foster motivation and engagement by providing conditions conducive to arriving at a work organization and technology that, according to Weick (2000), make sense to the clinicians. 
EDIT's contribution should be viewed in the light of the extensive investments in health care IT combined with the Danish Ministry of Health's decision to develop a new outcome-based quality development program. The call for a new quality development program emphasizes several ambitious national quality goals: the freedom to find local ways of obtaining quality goals, the ability to influence and own local quality-improvement efforts, and the establishment of continuous quality improvement using real-time data (Sundhedsministeriet, 2015). EDIT might substantially contribute to utilizing new IT in ways that optimize the quality of both patient treatment and working conditions. Health care IT changes the work organization, as illustrated with the introduction of Epic in the Capital Region and Region Zealand in Denmark. New IT also provides new opportunities for patient treatment, especially as a tool supporting interdisciplinary and cross-departmental collaboration, also called 'shared care' or 'the patient at the centre'. The EDIT example with the effect of obtaining a shorter fasting period illustrates how IT might support and improve coordination relating to prioritization and clinical decision-making when transferring patients for operation.

We suggest EDIT as an element of the new quality development program requested by the Danish Ministry of Health. National quality goals, such as value-based health care delivery (Porter, 2008), might be specified in terms of means-end hierarchies that link the goals to locally formulated technology-supported effects (see Table 1). Similarly, overall clinical guidelines such as the Danish cancer pathway program may form mandatory requirements and constraints in the hierarchy that effects must align to. Further research and development is needed to organize and govern the distribution, scaling, and dissemination of local successfully achieved effects throughout the health care sector. DQM may, in its current form or in a modified form, serve as a valuable source of knowledge about general process standards that support national quality goals. It may also offer strategies for enforcing and sustaining clinical standard guidelines. In contrast, the local experimentation and learning within EDIT might provide substantial input for revising processes or proposing new standards aimed at obtaining specific effects.

\section{Conclusion}

Accreditation is a widespread approach to quality development, supported by several international quality and standardization organizations. Among the Nordic countries, only Denmark has applied accreditation as the overall national strategy for quality development in the healthcare sector. The Danish experience of overimplementing accreditation resulting in bureaucracy and frustration among the clinicians (especially the physicians) has relevance for other Nordic countries. However, our main aim has been to address the need for balancing the process and standardization focus inherent in accreditation with participatory approaches that allow for local experimentation. This is especially relevant in relation to changes in work organization as a consequence of the massive investments in new technologies.

We have described EDIT, contrasted it to DQM, and suggested it as a contribution to a sustained focus on realizing locally specified effects that comply with national quality goals and guidelines. EDIT is grounded in a participatory design approach to the iterative improvement of work organisation and technology. Participatory design

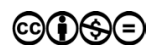


resembles a great deal of working life research by emphasizing the engagement, learning, motivation, and empowerment of the employees and by proposing that people are more inclined to engage in changing their ways of working if they are involved in defining what the problems are, what may solve them, and what the wished-for effects may be.

A participatory design approach like EDIT may inspire quality development programs and strategies to work organization and technology in other Nordic countries. EDIT is, we contend, in line with the Danish Ministry of Health's call for a new quality development program for the Danish health care sector, and may contribute by

- Offering a strategy for outcome control and the standardization of outputs (whereas DQM relies on behavior control and the standardization of processes).

- Iterating through the specification, realization, and assessment of wished-for effects (whereas DQM focuses on PDCA cycles to ensure process compliance).

- Establishing local quality goals in terms of effects that are aligned with national goals through a means-end hierarchy.

- Emphasizing effects to be specified locally by the affected clinicians, realized through local experiments and interventions, and assessed in formative evaluations based on real-world data about the outcomes.

- Allowing for ways of working that facilitate proficient and expert performance in addition to DQM's skill acquisition stages of novice, advanced beginner, and competent performance.

- Providing legitimate explanations from the 'inside' rather than the 'outside' - explanations that are energising and support new work practices in becoming routine behavior.

These bullet points summarize how EDIT aims to advance participatory design, which often struggles for organizational recognition. The introduction of EDIT as an approach to quality development will make participatory design integral to organizational development. DQM and EDIT may even coexist and mutually inform each other. We have particularly discussed (1) how overall evidence-based guidelines may be linked to the local effects and means necessary to achieve them and (2) how the local experimentation necessary to achieve effects may be used to revise existing or propose new clinical procedures. Local participation in the specification of effects and the experimentation with how to realize them will anchor decisions in local knowledge, thereby providing the staff with influence on their work as well as providing a more informed basis for guideline implementation.

Quality-assurance programs that, like DQM, focus on process standardization are also common in sectors other than health care. Thus, the need to complement DQM-like programs with approaches that are energising and open to local experimentation is not restricted to health care. This suggests that EDIT may be applicable in multiple sectors, such as engineering, government, and health care. It is, however, for future research to establish its applicability outside of health care because EDIT has, so far, been devised through IT-related projects in the health care sector. A distinctive characteristic of the health care sector with respect to EDIT (and other quality-development approaches) may be its dual emphasis on both professional clinical judgment and authoritative clinical guidelines. 


\section{Acknowledgements}

The project described in the section 'Example: EDIT at a hospital' was co-funded by Roskilde University and Region Zealand. We are grateful for the inspiring collaboration we have had with clincians at Nykøbing Falster Hospital, especially: Dorte Stilund Jensen, Helle Pia Dengsøe, Kija Lin Østergaard, Lene Hansen, Monica Hjorth Marqvorsen, and Ulrich Lichtenstein Andersen.

\section{References}

Bannon, L. J., \& Ehn, P. (2013). Design: design matters in Participatory Design. In J. Simonsen \& T. Robertson (Eds.), Routledge International Handbook of Participatory Design (pp. 37-63). New York, NY: Routledge. doi: https://www.routledgehandbooks. $\mathrm{com} /$ doi/10.4324/9780203108543.ch3.

Bansler, J. P., Havn, E. C., Schmidt, K., Mønsted, T., Petersen, H. H., \& Svendsen, J. H. (2016). Cooperative Epistemic Work in Medical Practice: An Analysis of Physicians' Clinical Notes. Computer Supported Cooperative Work (CSCW), 25(6), 503-546. doi: http:// link.springer.com/10.1007/s10606-016-9261-x.

Benner, P. (1982). From novice to expert. American Journal of Nursing, 82(3), 402-407. doi: http://dx.doi.org/10.2307/3462928.

Berg, M., Aarts, J., \& Lei, J. V. D. (2003). ICT in Health Care: Sociotechnical Approaches. Methods of Information in Medicine, 42(4), 297-301. doi: https:/www.ncbi.nlm.nih. gov/pubmed/14534625.

Bjerknes, G., Ehn, P., \& Kyng, M. (1987). Computers and Democracy - A Scandinavian Challenge. England: Avebury.

Bogh, S. B., Falstie-Jensen, A. M., Hollnagel, E., Holst, R., Braithwaite, J., \& Johnsen, S. P. (2016). Improvement in quality of hospital care during accreditation: A nationwide stepped-wedge study. International Journal for Quality in Health Care, 28(6), 715-720. doi: https://www.ncbi.nlm.nih.gov/pubmed/27578631.

Brandrup, M., Østergaard, K. J., Hertzum, M., Karasti, H., \& Simonsen, J. (2017). Effects-Driven Participatory Design: Learning from Sampling Interruptions. In A. M. Kanstrup, A. Bygholm, P. Bertelsen, \& C. Nøhr (Eds.), Participatory Design \& Health Information Technology (pp. 113-127). Amsterdam, The Netherlands: IOS Press. doi: https://doi.org/10.3233/978-1-61499-740-5-113.

Bratteteig, T., \& Wagner, I. (2016). Unpacking the Notion of Participation in Participatory Design. Computer Supported Cooperative Work (CSCW), 25(6), 425-475. doi: https:// doi.org/10.1007/s10606-016-9259-4.

Buchwaldt, P. (2014). Sundhedsplatformen [the Epic healthcare platform]. Presentation at the DIAG partner meeting given by the CIO of Region Zealand, Per Buchwaldt.

Bødker, K., Kensing, F., \& Simonsen, J. (2004). Participatory IT Design. Designing for Business and Workplace Realities. Cambridge, Massachusetts: MIT Press. doi: https://mitpress.mit.edu/books/participatory-it-design.

Clearinghouse. (2009). Klinisk retningslinje for håndhygiejne [Clinical guidelines for hand hygiene]. Center for kliniske retningslinier - Clearinghouse. doi: http://www. cfkr.dk/retningslinjer/godkendte-retningslinjer/hud-og-slimhinder/klinisk-retningslinje-for-haandhygiejne.aspx.

Deming, W. E. (1982). Out of the Crisis. Massachusetts: MIT-CAES.

Dreyfus, H. L., \& Dreyfus, S. E. (1986). Mind over Machine: The power of human intuitive expertise in the era of the computer. New York: Free Press. doi: https://dl.acm.org/citation.cfm?id=7916. 
Ehlers, L. H., Jensen, M. B., Simonsen, K. B., Rasmussen, G. S., \& Braithwaite, J. (2017). Attitudes towards accreditation among hospital employees in Denmark: a cross-sectional survey. International Journal for Quality in Health Care, 1-6. doi: https://doi. org/10.1093/intqhc/mzx090.

Ehn, P. (1988). Work-Oriented Design of Computer Artifacts. Stockholm, Sweden: Arbetslivcentrum. doi: https://doi.org/10.1002/sres.3850090411.

Eisenhardt, K. M. (1985). Control: Organizational and economic approaches. Management science, 31(2), 134-149. doi: https://doi.org/10.1287/mnsc.31.2.134.

Engel, C., \& Andersen, H. B. (2017). Side Effects of Overdoing It: Lessons from a Comprehensive Hospital Accreditation Programme. In K. Aase \& L. Schibevaag (Eds.) Researching Patient Safety and Quality in Healthcare: A Nordic Perspective, (pp. 115-130). London: CRC Press, Taylor and Francis Group. doi: http://dx.doi. org/10.1201/9781315605609.

Eriksson, A., Holden, R. J., Williamsson, A., \& Dellve, L. (2016). A Case Study of Three Swedish Hospitals' Strategies for Implementing Lean Production. Nordic Journal of Working Life Studies, 6(1), 105-131. doi: https://doi.org/10.19154/njwls.v6i1.4912.

Ernst, J. (2016). Evidence-based nursing in the IED: From caring to curing? Nordic Journal of Working Life Studies, 6(1), 47-66. doi: https://doi.org/10.19154/njwls.v6i1.4885.

Falstie-Jensen, A. M., Bogh, S. B., Hollnagel, E., \& Johnsen, S. P. (2017). Compliance with accreditation and recommended hospital care-a Danish nationwide population-based study. International Journal for Quality in Health Care, 1-9. doi: https://doi.org/10.1093/ intqho/mzx104.

Greenbaum, J., \& Kyng, M. (Eds.). (1991). Design at Work: Cooperative Design of Computer Systems. Chichester, UK: Lawrence Erlbaum Associates.

Greenfield, D., \& Braithwaite, J. (2008). Health sector accreditation research: a systematic review. International Journal for Quality in Health Care, 20(3), 172-183. doi: https://doi. org/10.1093/intqhc/mzn005.

Ellingsen, G., Monteiro, E., \& Munkvold, G. (2007). Standardization of Work: Co-constructed Practice. The Information Society, 23, 309-326. doi: https://doi. org/10.1080/01972240701572723.

Hasle, P., \& Sørensen, O. H. (2013). Employees as Individually and Collectively Acting Subjects-Key Contributions from Nordic Working Life Research. Nordic Journal of Working Life Studies, 3(3), 9-29. doi: http://dx.doi.org/10.19154/njwls.v3i3.3009.

Hertzum, M., \& Simonsen, J. (2008). Positive effects of electronic patient records on three clinical activities. International Journal of Medical Informatics, 77(12), 809-817. doi: https://doi.org/10.1016/j.ijmedinf.2008.03.006.

Hertzum, M., \& Simonsen, J. (2011a). Effects-Driven IT Development Specifying, Realizing, and Assessing Usage Effects. Scandinavian Journal of Information Systems, 23(1), 1-26. doi: http://aisel.aisnet.org/sjis/vol23/iss1/1/.

Hertzum, M., \& Simonsen, J. (2011b). Effects-Driven IT Development: Status 2004-2011. In M. Hertzum \& C. Jørgensen (Eds.), Balancing Sourcing and Innovation in Information Systems Development (pp. 165-192). Trondheim, NO: Tapir Academic Publishers. doi: http://jespersimonsen.dk/Downloads/EDIT Status2011 BSIISD2011 preprint.pdf.

Hertzum, M., \& Simonsen, J. (2016). Effects of electronic emergency-department whiteboards on clinicians' time distribution and mental workload. Health Informatics Journal, 22(1), 3-20. doi: https://doi.org/10.1177/1460458214529678.

Hvid, H., Bergholm, T., Gonäs, L., Juul, I., Kamp, A., Karlsson, J. et al. (2011). Nordic Working Life Research - Continuity and Renewal. Nordic journal of working life studies, 1(1), 3-21. doi: https://doi.org/10.19154/njwls.v1i1.2333.

IKAS. (2013). Akkrediteringsstandarder for sygehuse, 2. version, 2. udgave [Accreditation standards for hospitals (2nd ed.)]. Aarhus, Denmark: IKAS, Institut for Kvalitet og 
Akkreditering i Sundhedsvæsenet [Danish Institute for Quality and Accreditation in Health Care]. doi: http://www.ikas.dk/FTP/PDF/D12-6522.pdf.

IKAS. (2014). Trygd \& Dygd: Dygdarshipan fyri føroyska sjúkrahúsverkið, Akkrediteringsstandardir, 1. útgáva [Accreditation standard for hospitals on the Faroe Islands]. Institut for Kvalitet og Akkreditering $i$ Sundhedsvosenet, IKAS. doi: http://www.ikas.dk/ftp/pdf/ d15-9328.pdf.

IKAS. (2015). Akkrediteringsstandarder for Sørlandet sykehus HF, Klinikk for psykisk helse 1. version, 1. udgave [Accreditation standard for Sørlandet hospital]. Institut for Kvalitet og Akkreditering $i$ Sundhedsvosenet, IKAS. doi: http://www.ikas.dk/FTP/PDF/D1510543.pdf.

Ingeman, M. L., Christensen, M. B., Bro, F., Knudsen, S. T., \& Vedsted, P. (2015). The Danish cancer pathway for patients with serious non-specific symptoms and signs of cancer-a cross-sectional study of patient characteristics and cancer probability. BMC Cancer, 15(421), 1-11. doi: https://doi.org/10.1186/s12885-015-1424-5.

Kamp, A., \& Dybbroe, B. (2016). Struggles of Professionalism and Emotional Labour in Standardized Mental Health Care. Nordic journal of working life studies, 6(1), 67-86. doi: https://doi.org/10.1186/s12885-015-1424-5.

Kensing, F., \& Greenbaum, J. (2013). Heritage: Having a say. In J. Simonsen \& T. Robertson (Eds.), Handbook of Participatory Design (pp. 21-36). Routledge. doi: https://www.routledgehandbooks.com/doi/10.4324/9780203108543.ch2.

Mainz, J., Bartels, P., Rhode, P., Pedersen, K. M., Bek, T., \& Krøll, V. (2011). Kvalitetsudvikling i praksis [Quality development in practice]. Copenhagen, Denmark: Munksgaard. doi: http://munksgaard.dk/Medicin/Kvalitetsudvikling-i-praksis/9788762807143.

Klein, G. O. (2002). Standardization of Health Informatics - Results and Challenges. Methods Archive, 41(4), 261-270. doi: https://www.ncbi.nlm.nih.gov/pubmed/12425236.

Lie, A., \& Bjørnstad, O. (2015). Accreditation of occupational health services in Norway. Occupational Medicine, 65(9), 722-724. doi: https://doi.org/10.1093/occmed/kqv120.

Mintzberg, H. (1980). Structure in the 5's: A Synthesis of the Research on Organization Design. Management Science, 26(3), 322-341. doi: https://doi.org/10.1287/mnsc.26.3.322.

Nicklin, W., Fortune, T., van Ostenberg, P., O’Connor, E., \& McCauley, N. (2017). Leveraging the full value and impact of accreditation. International Journal for Quality in Health Care, 29(2), 310-312. doi: https://doi.org/10.1093/intqhc/mzx010.

Norén, L., \& Ranerup, A. (2015). Promoting competition in Swedish primary care. Journal of Health Organization and Management, 29(1), 25-38. doi: https://oi.org/10.1108/ JHOM-04-2012-0080.

Nygaard, K. (1979). The 'iron and metal project': Trade union participation. In Å. Sandberg (Ed.), Computers Dividing Man and Work (pp. 94-107). Stockholm: Swedish Center for Working Life.

Nygaard, K. (1996). 'Those Were the Days'? Or 'Heroic Times Are Here Again'? Scandinavian Journal of Information Systems, 8(2), 91-108. doi: http://aisel.aisnet.org/sjis/vol8/ iss $2 / 6 /$.

Oudhuis, M., \& Tengblad, S. (2013). Experiences from Implementation of Lean Production: Standardization versus Self-management: A Swedish Case Study. Nordic Journal of Working Life Studies, 3(1), 31-48. doi: http://dx.doi.org/10.19154/njwls.v3i1.2519.

Porter, M. E. (2008). Value-Based Health Care Delivery. Annals of Surgery, 248(4), 503-509. doi: https://doi.org/10.1097/SLA.0b013e31818a43af.

Ramstad, E. (2015). Can High-involvement Innovation Practices improve Productivity and the Quality of Working-life simultaneously? Management and Employee Views on Comparison. Nordic Journal of Working Life Studies, 4(4), 25-45. doi: http://dx.doi. org/10.19154/njwls.v4i4.4706. 
Rasmussen, J., Pejtersen, A. M., \& Goodstein, L. P. (1994). Cognitive Systems Engineering. John Wiley and Sons, Inc. doi: https://www.wiley.com/en-us/Cognitive+Systems+Engineering-p-9780471011989.

Rasmussen, R., Fleron, B., Hertzum, M., \& Simonsen, J. (2010). Balancing Tradition and Transcendence in the Implementation of Emergency- Department Electronic Whiteboards. In J. Molka-Danielsen, H. W. Nicolajsen, \& J. S. Persson (Eds.), IRIS Selected Papers of the Information Systems Research Seminar in Scandinavia - Nr. 1 (2010): IRIS 33, Engaged Scandinavian Research (pp. 73-88). Trondheim, NO: Tapir Academic Publishers. doi: http://jespersimonsen.dk/Downloads/Balancing $\% 20$ Tradition $\% 20$ and $\% 20$ Transcendence $\% 20$ in $\% 20$ the $\% 20$ Implementation $\% 20$ of $\% 20$ Emergency- $\% 20$ Department $\% 20$ Electronic $\% 20$ Whit.pdf.

Simonsen, J., \& Hertzum, M. (2012). Sustained Participatory Design: Extending the Iterative Approach. Design Issues, 28(3), 10-21. doi: http://dx.doi.org/10.1162/DESI a 00158.

Simonsen, J., \& Robertson, T. (Eds.). (2013). Routledge International Handbook of Participatory Design. New York, NY: Routledge. doi: https:/www.routledgehandbooks.com/ doi/10.4324/9780203108543.

Simonsen, J., Hertzum, M., \& Barlach, A. (2011). Experiences with effects specifications. In M. Hertzum \& C. Jørgensen (Eds.), Balancing Sourcing and Innovation in Information Systems Development (pp. 145-164). Trondheim, NO: Tapir Academic Publishers. doi: https://doi.org/10.1162/DESI a 00158.

Sokovic, M., Pavletic, D., \& Pipan, K. K. (2010). Quality improvement methodologies-PDCA cycle, RADAR matrix, DMAIC and DFSS. Journal of Achievements of Materials and Manufacturing Engineering, 43(1), 476-483. doi: http://jamme.acmsse.h2.pl/papers vol43 1/43155.pdf.

Sundhedsministeriet. (2015). Nationalt kvalitetsprogram for sundhedsområdet 2015-2018 [National quality program for the healtcare sector 2015-2018]. Sundheds og celdreministeriet [Ministry of Health]. doi: https://www.sum.dk/ /media/Filer\%20-\%20Publikationer i pdf/2015/Nationalt-kvalitetsprogram-for-sundhedsomraadet/Nationalt $\% 20$ kvalitetsprogram \%20for\%20sundhedsområdet \%20-\%20april\%202015.pdf.

Taylor, M. J., McNicholas, C., Nicolay, C., Darzi, A., Bell, D., \& Reed, J. E. (2014). Systematic review of the application of the plan-do-study-act method to improve quality in healthcare. BMJ Quality and Safety, 23(4), 290-298. doi: https://doi.org/10.1136/bmiqs-2013-001862.

Weick, K. E. (2000). Quality improvement - A sensemaking perspective. In R. E. Cole \& R. W. Scott (Eds.), The quality movement and organization theory (pp. 155-172). Thousand Oaks, CA: Sage. doi: https://us.sagepub.com/en-us/nam/the-quality-movement-and-organization-theory/book 9893 .

WHO. (2003). Quality and accreditation in health care services: a global review. apps.who. int. doi: http://apps.who.int/iris/bitstream/10665/68410/1/WHO EIP OSD 2003.1.pdf.

WHO. (2006). Implementing health promotion in hospitals: Manual and self-assessment forms. apps.who.int. doi: http://apps.who.int/iris/bitstream/10665/107737/1/E88584.pdf.

Wihlman, T., Hoppe, M., Wihlman, U., \& Sandmark, H. (2014). Employee-driven Innovation in Welfare Services. Nordic Journal of Working Life Studies, 4(2), 159-180. doi: http:// dx.doi.org/10.19154/njwls.v4i2.3869. 